\title{
Analysis of the Surgical Outcome and Prognostic Factors for Hilar Cholangiocarcinoma: A Chinese Experience
}

\author{
Huikai Li ${ }^{\mathrm{a}}$ Yu Qin ${ }^{\mathrm{b}}$ Yunlong Cui ${ }^{\mathrm{a}}$ Hua Chen ${ }^{c}$ Xishan Hao ${ }^{\mathrm{a}}$ Qiang $\mathrm{Li}^{\mathrm{a}}$ \\ ${ }^{a}$ Department of Hepatobiliary Surgery, Tianjin Medical University Cancer Institute and Hospital, ${ }^{b}$ Department of \\ Diagnostics, Tianjin Medical University, and ' Department of Pathology, Tianjin Medical University Cancer Institute \\ and Hospital, Tianjin, China
}

\section{Key Words}

Hilar cholangiocarcinoma - Staging · Surgical procedures •

Prognostic factors

\begin{abstract}
Purposes: Hilar cholangiocarcinoma (HC) is the most common location for bile duct cancer. It represents a significant technical challenge for surgical operation due to the close proximity to major vascular structures and to the liver and arborization of the right and left biliary tree. The objective of this study was to assess the therapeutic strategies and prognostic factors that could influence the clinical outcome of HC. Methods: From January 1990 to December 2009, a total of $215 \mathrm{HC}$ patients undergoing resection were included in this study. Survival and follow-up were calculated from the date of initial histologic diagnosis to the dates of first recurrence or death and last contact, respectively. Uni- and multivariate analyses were performed to examine factors affecting clinical outcome and recurrence. Results: 215 patients underwent resection: 141 (65.6\%) had an R0 resection (negative histologic margins), 46 (21.4\%) had an R1 resection (positive histologic margins), 28 (13.0\%) had an R2 resection. The 1-, 3- and 5 -year cumulative survival rates (\%) of the patients were 60.3 , 37.2 and $29.7 \%$. The median survival time after Ro resection
\end{abstract}

was 47.1 months, 17.2 months after R1 resection, and 12.1 months after $\mathrm{R} 2$ resection. The results from univariate analyses suggest that poor histopathological grade $(p=0.004)$, lymph node metastasis $(p=0.000)$, vascular invasion $(p=$ $0.005)$, neuroinvasion $(p=0.044), R 1$ resection $(p=0.000)$ and T2 or T3 stage ( $p=0.009)$ were significant predictors for poor survival rates. By multivariate analysis, only the lymph node metastasis ( $R R=2.450,95 \% \mathrm{Cl} 1.677-3.579)$ and $\mathrm{R} 1$ resection $(\mathrm{RR}=0.283,95 \% \mathrm{Cl} 0.183-0.437)$ were significantly associated with poor survival rates. Conclusions: Negative histologic margins were associated with improved outcome after all HC resections. Complete resection remains the only therapy that offers the possibility of long-term survival, and hepatic resection is a critical component of the surgical approach.

Copyright $\odot 2011$ S. Karger AG, Basel

\section{Introduction}

Hilar cholangiocarcinoma (HC), also known as Klatskin's tumor, is a relatively rare tumor typically affecting the hepatic duct confluence. Surgical treatment is difficult because of the tumor's central location in the liver hilum and its intimate relationships with the adjacent liver parenchyma, portal vein, and hepatic arteries

\section{KARGER}

Fax +4161306 1234 E-Mail karger@karger.ch www.karger.com (c) 2011 S. Karger AG, Basel

0253-4886/11/0283-0226\$38.00/0

Accessible online at:

www.karger.com/dsu
Dr. Qiang Li

Department of Hepatobiliary Surgery

Cancer Hospital of Tianjin Medical University

Tianjin 300060 (China)

Tel. +86 1382037 7269, E-Mail thebeatleshui@yahoo.com.cn 
[1]. Surgical treatment of HC has changed greatly in recent decades: before 1980, the majority of patients were not resected, and in a few cases local excision of the tumor was performed with low radicality and poor long-term outcome. Since 1980, indications for resection have progressively improved and liver resection has been associated with bile duct resection in order to increase radicality and achieve better survival results $[2,3]$. In this era, the perioperative management of $\mathrm{HC}$ has improved markedly. Several advances in surgical techniques and technology have contributed to these improvements.

In China, a large number of patients undergo surgical resection for this disease, yet studies examining their survival and cancer recurrence are scant. Therefore, the aim of this study was to review our surgical experiences with $\mathrm{HC}$ by focusing on the outcomes of patients treated over the past 20 years.

\section{Patients and Methods}

A review of all patients who underwent a surgical exploration for proximal bile duct carcinoma was carried out. The participants of this study were 215 patients receiving resection for $\mathrm{HC}$ at the Tianjin Medical University Cancer Hospital (TMUC) between January 1990 and December 2009. Diagnosis of HC was determined prior to surgery through at least two of the following four diagnostic procedures: ultrasonography, plain or enhanced computed tomography (CT), magnetic resonance imaging or magnetic resonance cholangiopancreatography, and percutaneous or endoscopic retrograde cholangiopancreatography. Percutaneous transhepatic biliary drainage or endoscopic nasobiliary drainage was performed in most of patients with obstructive jaundice. None of the reviewed patients underwent a preoperative portal vein embolization.

Hilar tumors were typically treated with partial hepatectomy, cholecystectomy, bile duct resection and porta hepatic lymphadenectomy en bloc. Operative assessment for tumor respectability was performed according to previously described methods. Resection of all lymph nodes within the pericholedochal and periportal station and common hepatic artery was routinely performed. Caudate lobectomy was performed for all tumors involving the left hepatic duct and in selected additional cases arising from the right hepatic duct in order to achieve complete tumor resection. Biliary continuity was achieved by Roux-en-Y hepaticojejunostomy. Frozen-section pathologic examination of cut ends of ducts was routinely used to guide resection; additional ductal resection inside the pancreas was performed if the distal bile duct margin was initially tumor-positive.

Post hoc pathological verification was performed for all cases. Curative surgery was defined as complete resection of all macroand microscopic tumors. The diagnosis of $\mathrm{HC}$ for these patients was pathologically confirmed. The absence of tumor cells along the parenchymal transection line was confirmed histologically. Confirmation of no remaining tumor in the remnant liver was done by CT, 3-4 weeks postoperatively. Tumor staging was patho- logically performed in accordance with the American Joint Commission on Cancer (AJCC) staging system (6th edition), T-staging system [4] and Bismuth-Corlette's classification [5]. An R0 resection was defined as the absence of tumor cells at all resection margins, while any margin involvement defined an R1 resection.

Patients given resection were followed up at the outpatient clinic every 3 months with measurement of serum CA19-9 level and hepatic ultrasonography, and every 6 months with a chest Xray. When recurrence was suspected, further evaluations were made by abdominal CT scan and/or angiography of the celiac trunk with lipiodol injection and, if necessary, by ultrasoundguided biopsy to confirm the diagnosis. Study follow-up ended on January 31, 2010.

\section{Statistical Analysis}

Medical records and survival data were obtained for all patients. Death occurring within 30 days after the surgical procedure was defined as an operative mortality. Death occurring after surgery and before discharge was defined as a hospital mortality. Survival was considered from the day of surgery to the day of death or the most recent follow-up visit. Clinical features and pathologic tumor-related factors were compared with the Wilcoxon rank sum test and the Student's $t$ test, or $\chi^{2}$ test. The Kaplan-Meier method was used to estimate the cumulative probabilities of recurrence and patient survival and differences in the probabilities were evaluated using the log-rank test. Cox's proportional hazards model, in which a stepwise selection is used for variable selection with entry and removal limits of $p<0.1$ and $>0.15$, respectively, was performed to identify factors that were independently associated with the development of recurrence. Differences associated with $p$ values $<0.05$ were considered significant. Statistical analysis was carried out using SPSS 16.0.

\section{Results}

Since January 1990, 573 consecutive patients with HC have been evaluated. 322 (56.2\%) were considered for an operation but only 243 (42.4\%) had an attempt at complete resection. Perioperative mortality was $4.5 \%$ (11 of 243), during the follow-up, 17 cases were lost. Of the 215 study patients, 141 (65.6\%) had clear surgical margins (R0), 46 (21.4\%) had an R1 resection (positive histologic margins), and 28 (13.0\%) had an $\mathrm{R} 2$ resection (table 1 ).

Of the 187 resection patients $(\mathrm{R} 0+\mathrm{R} 1)$, according to Bismuth-Corlette's classification, tumors were classified as four types: type I, 41 patients (21.9\%); type II, 70 patients (37.4\%); type IIIA, 19 patients (10.2\%); type IIIB, 29 patients (15.5\%) and type IV 28 patients (15.0\%). According to the AJCC staging system, tumors were staged as: stage I ( $\mathrm{n}=31,16.5 \%)$, stage II $(\mathrm{n}=121,64.7 \%)$, stage III $(\mathrm{n}=28,15.0 \%)$ and stage IV $(\mathrm{n}=7,3.7 \%)$. Histopathologically, a highly differentiated adenocarcinoma (G1) was found in 69 patients (36.9\%), a poorly differentiated adenocarcinoma (G2, G3, G4) in 118 patients (63.1\%), and 
Table 1. HC at TMUC: summary of patients evaluated 1990-2009

\begin{tabular}{lc}
\hline & 573 consecutive patients \\
\hline Mean age & 57 \\
Male gender & $60.2 \%$ \\
Unresectable at presentation & $251(43.8 \%)$ \\
Unresectable at exploration & $79(13.8 \%)$ \\
Resection & 215 \\
$\quad$ R0 & $141(65.6 \%)$ \\
R1 & $46(21.4 \%)$ \\
R2 & $28(13.0 \%)$ \\
Operative mortality & $11(4.5 \%)$ \\
\hline
\end{tabular}

lymph node metastases were found in 98 (52.4\%) patients. Vascular invasion was found in 71 patients (38.0\%), of which 34 were microinvasive and 37 were macroinvasive. At the same time, neuroinvasion was found in 42 patients.

Besides 10 (5.3\%) bile duct resections alone, combined hepatectomy was carried out in 177 (94.7\%) of 187 resections. Major hepatectomy, including right or left hemihepatectomy and trisectionectomy, was performed in 103 of the 187 liver resections (table 2). Hepatopancreatoduodenectomy was performed in 5 (2.7\% of combined hepatectomy) selected patients with diffuse bile duct cancer to secure a negative distal bile duct margin. Of those patients who underwent a potentially curative resection, 30 required portal vein resection and 11 had a hepatic artery resection, while 6 required a simultaneous vein and arterial reconstruction. All patients had a regional lymphadenectomy. Several kinds of postoperative complications occurred in a total of $91(41.2 \%)$ patients. Intra-abdominal abscess, observed in 32 (13.2\%) patients, was the most common complication, followed by bile leakage from the liver stump (21 patients, 8.6\%) and wound sepsis (17 patients, 7.0\%). Liver failure, defined as a serum total bilirubin concentration of $>10 \mathrm{mg} / \mathrm{dl}$ [6], was observed in 8 (3.3\%) patients.

215 patients underwent resection: 141 (65.6\%) had an R0 resection, 46 (21.4\%) had an R1 resection, and 28 (13.0\%) had an R2 resection. The 1-, 3- and 5-year cumulative survival rates (\%) of the patients were $60.3,37.2$, and $29.7 \%$. The median survival time after R0 resection was 47.1 months, 17.2 months after $\mathrm{R} 1$ resection, and 12.1 months after $\mathrm{R} 2$ resection ( $<<0.01$ ) (fig. 1). Survival after resection in patients with negative lymph nodes was significantly longer than in those with positive lymph nodes $(\mathrm{p}<0.01)$ (fig. 2). The T-stage system predicted respectability and the likelihood of an $\mathrm{R} 0$ resection and corre-
Table 2. Surgical procedures performed

\begin{tabular}{lccccc}
\hline Resection procedure & \multicolumn{3}{l}{ Patients, $\mathrm{n}$} & & \\
\cline { 2 - 6 } & $\begin{array}{l}\text { total } \\
\text { with } \\
\text { S1 }\end{array}$ & $\begin{array}{l}\text { with } \\
\text { PV }\end{array}$ & $\begin{array}{l}\text { with } \\
\text { HA }\end{array}$ & $\begin{array}{l}\text { with } \\
\text { PD }\end{array}$ \\
\hline Bile duct resection & 10 & & & & 4 \\
Hepatectomy & 14 & 13 & 5 & 2 & \\
$\quad$ S4, 5, 6, 7, & 29 & 16 & 4 & 3 & \\
$\quad$ S5, 6, 7, 8 & 25 & 18 & 5 & 1 & \\
S2, 3, 4, 5, & 35 & 12 & 6 & 2 & \\
$\quad$ S2, 3, 4 & 33 & 25 & 2 & 2 & \\
$\quad$ S4, 5, 8 & 41 & 12 & 8 & 1 & 1 \\
Other segmentectomies & 187 & 96 & 30 & 11 & 5 \\
\hline Total & & & & & \\
\hline
\end{tabular}

$\mathrm{PV}=$ Portal vein resection; $\mathrm{HA}=$ hepatic artery resection; $\mathrm{PD}=$ pancreatoduodenectomy.

Table 3. Univariate analysis of factors affecting survival of 187 patients undergoing resection

\begin{tabular}{lrlll}
\hline Variable & $\begin{array}{l}\text { Patients } \\
\mathrm{n}\end{array}$ & $\begin{array}{l}\text { 5-year } \\
\text { survival } \\
\text { rate, } \%\end{array}$ & $\chi^{2}$ & p value \\
& & & \\
\hline Histopathological grade & & & & \\
$\quad$ G1 & 69 & 51.6 & 8.274 & 0.004 \\
$\quad$ G2-4 & 118 & 28.6 & & \\
LN metastasis & & & & \\
$\quad$ N0 & 89 & 55.9 & 35.007 & 0.000 \\
$\quad$ N1-2 & 98 & 12.1 & & \\
Vascular invasion & 116 & 36.2 & & \\
$\quad$ Absent & 71 & 20.7 & & 0.005 \\
$\quad$ Present & 145 & 37.8 & & \\
Neuroinvasion & 42 & 15.4 & 4.050 & 0.044 \\
$\quad$ Absent & & & & \\
$\quad$ Present & 141 & 40.6 & 49.701 & 0.000 \\
Curability & 46 & 0 & & \\
$\quad$ R0 & & & & \\
$\quad$ R1 & 68 & 43.0 & 6.867 & 0.009 \\
T stage & 119 & 26.9 & & \\
$\quad$ T1 & & & & \\
T2-T3 & & & & \\
\hline
\end{tabular}

lated with survival $(\mathrm{p}=0.009)$ (fig. 3). Patients requiring portal vein or hepatic artery resection had a worse prognosis than those without vascular resection $(\mathrm{p}=0.005)$, but still survived longer than patients who were unresectable (fig. 4). At the same time, univariate analysis also 


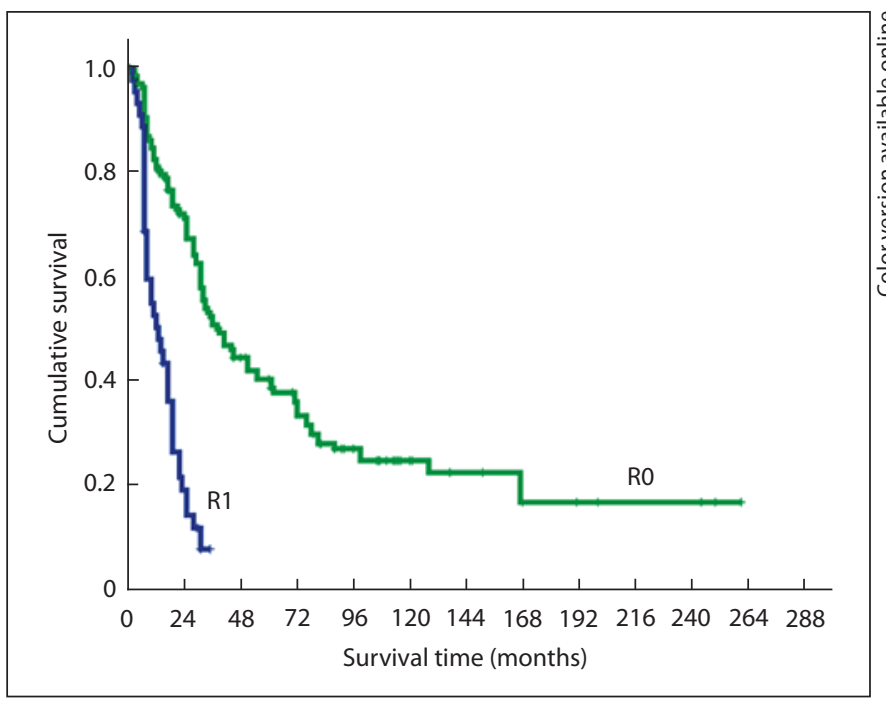

Fig. 1. Overall cumulative survival rate for patients with $\mathrm{HC}$ undergoing resection according to curability status. Overall cumulative survival rate was significantly worse in the $\mathrm{R} 1$ group than in the $\mathrm{R} 0$ group $(\mathrm{p}=0.000)$.

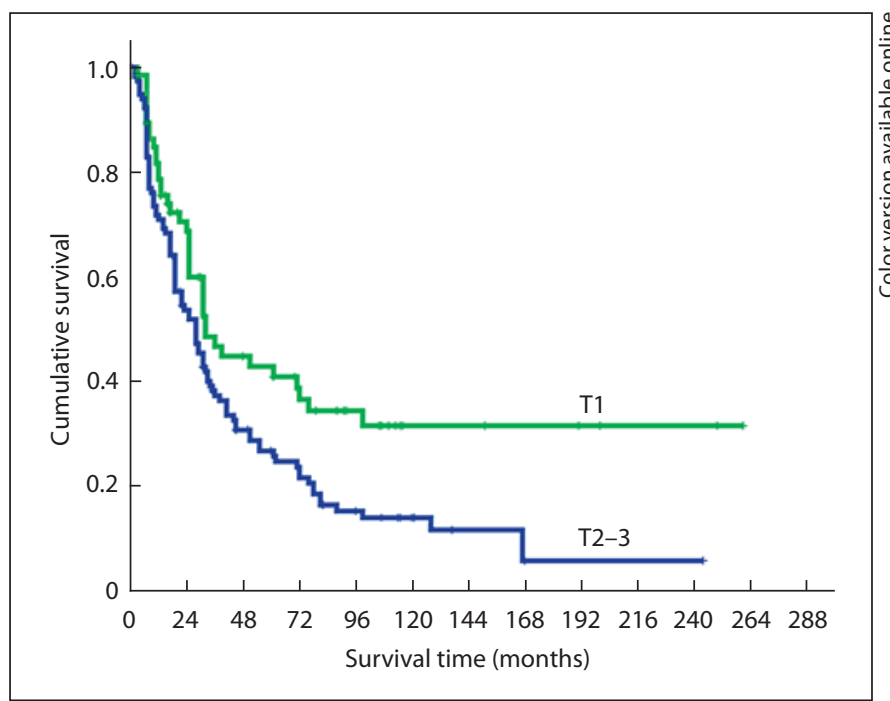

Fig. 3. Overall cumulative survival rate for patients with HC undergoing resection according to their $\mathrm{T}$ stage. Overall cumulative survival rate was significantly worse in the T2 -3 groups than in the $\mathrm{T} 1$ group $(\mathrm{p}=0.009)$.

revealed that neuroinvasion and poor histopathological grade were all significant predictors of poor survival (table 3). The results from the multivariate proportional hazard analysis are shown and only lymph node metastasis ( $\mathrm{RR}=2.450,95 \%$ CI 1.677-3.579) and R1 resection

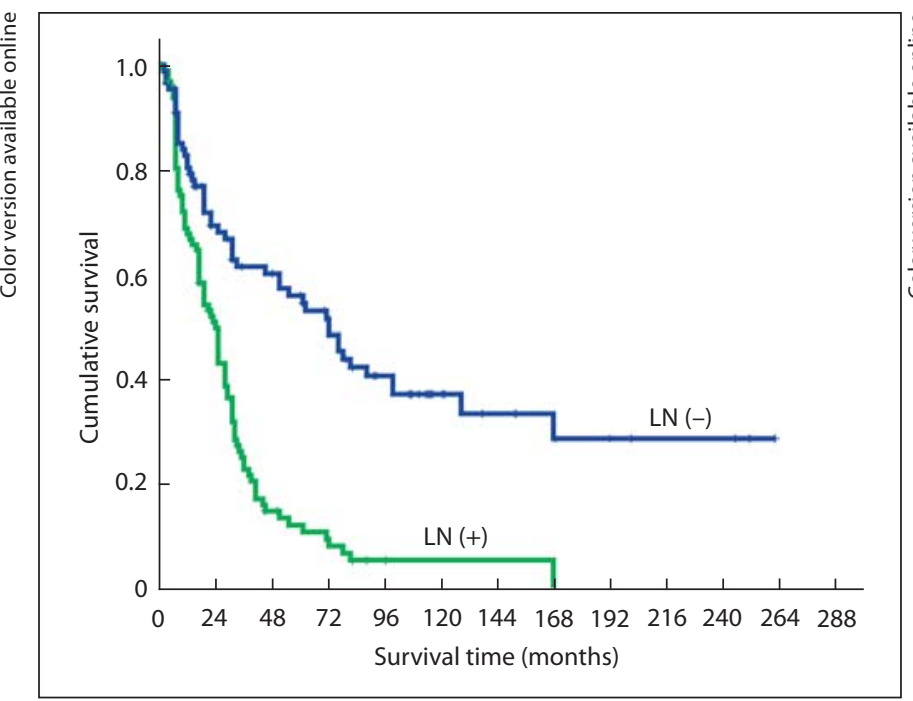

Fig. 2. Overall cumulative survival rate for patients with HC undergoing resection according to their lymph node (LN) status. Overall cumulative survival rate was significantly worse in the $\mathrm{LN}$ metastases (+) group than in the LN metastases $(-)$ group $(\mathrm{p}=$ $0.000)$.

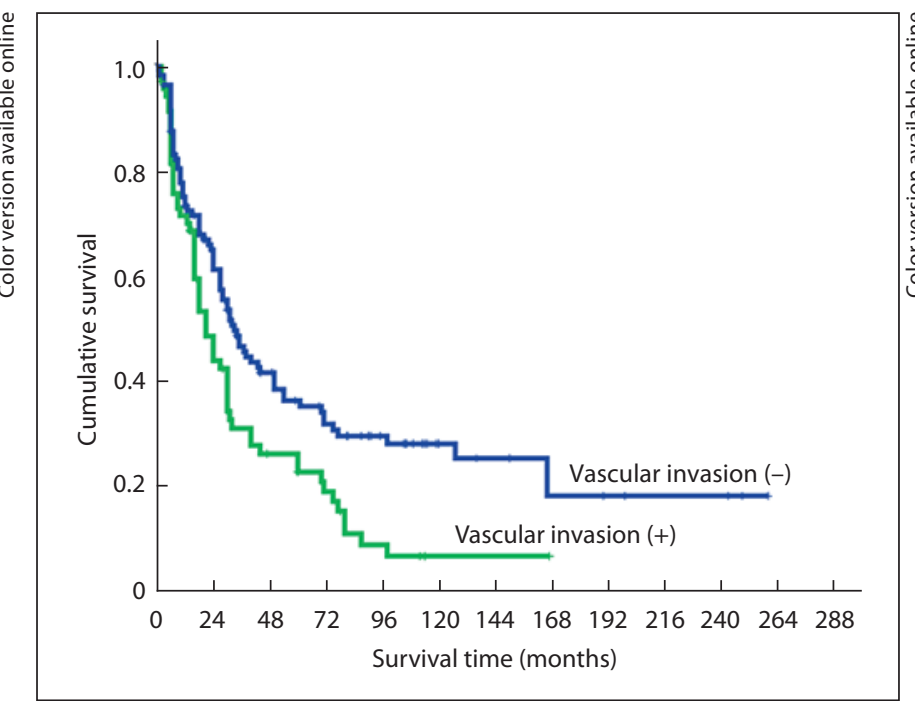

Fig. 4. Overall cumulative survival rate for patients with $\mathrm{HC}$ undergoing resection according to vascular invasion status. Overall cumulative survival rate was significantly worse in the vascular invasion $(+)$ group than in the vascular invasion $(-)$ group $(\mathrm{p}=$ $0.005)$.

$(\mathrm{RR}=0.283,95 \% \mathrm{CI} 0.183-0.437)$ were significantly associated with poor survival rates. However, there were no statistically significant impacts on survival rates for histopathological grade, $\mathrm{T}$ stage, vascular invasion (including micro- and macroinvasion) and neuroinvasion. 


\section{Discussion}

$\mathrm{HC}$ is the most common location for bile duct cancer. It represents a significant technical challenge due to the close proximity to major vascular structures and to the liver and arborization of the right and left biliary tree. In the last 20 years, surgical management of $\mathrm{HC}$ has evolved due to improvements in preoperative imaging and an enhanced appreciation of tumor growth characteristics. For example, multidetector-row CT has made it possible to accurately diagnose the extent of cancer [7]. Portal vein embolization has certainly increased the safety of extended hepatectomy [8], and has resulted in the recognition that liver resection is necessary to manage both direct hepatic invasion and the longitudinal intraductal extension that typically characterize HC $[4,9,10]$.

The accumulated results from many centers show convincingly that only a resection with negative histologic margins can be considered potentially curative and that hepatic resection is often required to achieve this objective $[11,12]$. Our results show the importance of partial hepatectomy in achieving a complete resection and further suggest that only a concomitant hepatic resection effectively clears all disease and offers the possibility of prolonged survival. Local recurrence within the hilar resection bed is a significant problem after removal of a perihilar cholangiocarcinoma. To decrease local recurrence, some groups are advocating routine removal of segment I (caudate). The caudate and caudate process that connects it to the liver typically lies just posterior to the bifurcation of the bile ducts and portal veins. There are usually multiple small caudate bile ducts that drain into the main biliary tree very close to the bifurcation [13].

Currently, no clinical staging system embraces all of the relevant local, tumor-related variables before surgery into subgroups based on potential for resection. BismuthCorlette's modified system classifies patients based on the extent of biliary ductal involvement by tumor; although useful to some extent, it does not correlate with respectability or survival. The AJCC TNM staging system is most commonly used to stage HC. However, this system is based on pathologic criteria and does not provide information on the potential for resectability. The Memorial Sloan-Kettering group has proposed a preoperative staging system, using data from preoperative imaging studies, based on biliary ductal involvement, vascular involvement, and lobar atrophy. This clinical T-staging system accounts for local tumor extent and correlates closely with resectability and survival [14].
Another contribution that allowed expansion of the surgical indications was the addition of aggressive vascular resections. Portal vein resection and reconstruction are now considered a routine procedure that is performed, when necessary, in high-volume centers. This concept has been advanced further by Neuhaus et al. [15] who have advocated routine resection of the portal vein bifurcation en bloc with the specimen including the caudate, with portal vein reconstruction between the main and left portal veins. This theoretically will clear all tissues at risk surrounding the periportal bile duct. So far, we have also performed portal vein resection in 86 patients with HC. In addition to portal vein resection, the hepatic artery resection and reconstruction procedure was adopted about 10 years ago, and its use has increased each year. In the present series, a total of 11 patients underwent concomitant hepatic artery resection and reconstruction with or without portal vein resection. Several authors reported dismal surgical outcomes of hepatectomy with concomitant hepatic artery resection [16-18]. However, the satisfactory results of Lee et al. [19] may encourage hepatobiliary surgeons to attempt this challenging surgical procedure.

Preoperative bile replacement during external drainage [20] and perioperative symbiotic treatment [21] have reduced postoperative infectious complication rates. Thanks to these recent advances in perioperative management, the surgical outcomes of patients with HC may have improved. However, 5 -year survival rates vary from 25 to $40 \%$ in recently published series. Many clinicopathological factors have been shown to have a positive impact on long-term outcome, including negative histologic margin status [10,22, 23], concomitant hepatic resection $[4,17,24]$, lack of nodal involvement $[25,26]$, lower AJCC T stage [27], well-differentiated tumor grade [28], papillary tumor morphology [29], and lack of perineural invasion $[12,30]$. Prognostic factors on univariate analysis in this study were the presence of residual tumor after resection, histological differentiation, vascular invasion, $\mathrm{T}$ stage and lymph node metastasis. In conclusion, radical surgical resection is the best treatment option for HC. R0 resection provides acceptable 5-year survival, although several other variables such as the histological tumor differentiation influence the prognosis.

\section{Conclusions}

Negative histologic margins concomitant with partial hepatectomy and well-differentiated tumor histology were associated with improved outcome after all $\mathrm{HC}$ re- 
sections. In patients who underwent an R0 resection, concomitant partial hepatectomy was the only independent predictor of long-term survival. The T-stage system predicted respectability and the likelihood of an R0 resection and correlated with survival. Complete resection remains the only therapy that offers the possibility of long-term survival, and hepatic resection is a critical component of the surgical approach.

\section{Acknowledgements}

This study was supported by the Department of Hepatobiliary Surgery, Cancer Hospital of Tianjin Medical University. The authors thank the Epidemiology Unit of Tianjin Centre for Disease Control for their technological support.

\section{Disclosure Statement}

None of the authors has any conflict of interest to declare.

\section{References}

1 Van Gulik TM, Gouma DJ: Changing perspectives in the assessment of resectability of hilar cholangiocarcinoma. Ann Surg Oncol 2007;14:1969-1971.

-2 Saldinger PF, Blumgart LH: Resection of hilar cholangiocarcinoma - a European and United States experience. J Hepatobiliary Pancreat Surg 2000;7:111-114.

- 3 Dinant S, Gerhards MF, Rauws EA, Busch OR, Gouma DJ, van Gulik TM: Improved outcome of resection of hilar cholangiocarcinoma (Klatskin tumor). Ann Surg Oncol 2006;13:872-880.

-4 Jarnagin WR, Fong Y, DeMatteo RP, et al: Staging, resectability, and outcome in 225 patients with hilar cholangiocarcinoma. Ann Surg 2001;234:507-519.

5 Bismuth H, Corlette MB: Intrahepatic cholangioenteric anastomosis in carcinoma of the hilus of the liver. Surg Gynecol Obstet 1975;140:170-178.

6 Nagino M, Kamiya J, Uesaka K, et al: Complications of hepatectomy for hilar cholangiocarcinoma. World J Surg 2001;25:12771283.

7 Sugiura T, Nishio H, Nagino M, et al: Value of multidetector-row computed tomography in diagnosis of portal vein invasion by perihilar cholangiocarcinoma. World J Surg 2008;32:1478-1484.

-8 Nagino M, Kamiya J, Nishio H, Ebata T, Arai T, Nimura Y: Two hundred forty consecutive portal vein embolizations before extended hepatectomy for biliary cancer: surgical outcome and long-term follow-up. Ann Surg 2006;243:364-372.

-9 Beazley RM, Hadjis N, Benjamin IS, Blumgart LH: Clinicopathological aspects of high bile duct cancer. Experience with resection and bypass surgical treatments. Ann Surg 1984; 199:623-636.

10 Kosuge T, Yamamoto J, Shimada K, Yamasaki S, Makuuchi M: Improved surgical results for hilar cholangiocarcinoma with procedures including major hepatic resection. Ann Surg 1999;230:663-671.
-11 Pichlmayr R, Weimann A, Klempnauer J, et al: Surgical treatment in proximal bile duct cancer. A single-center experience. Ann Surg 1996;224:628-638.

12 Nimura Y, Kamiya J, Kondo S, et al: Aggressive preoperative management and extended surgery for hilar cholangiocarcinoma: Nagoya experience. J Hepatobiliary Pancreat Surg 2000;7:155-162.

13 Mizumoto R, Suzuki H: Surgical anatomy of the hepatic hilum with special reference to the caudate lobe. World J Surg 1988;12:2-10.

14 Burke EC, Jarnagin WR, Hochwald SN, Pisters PW, Fong Y, Blumgart LH: Hilar cholangiocarcinoma: patterns of spread, the importance of hepatic resection for curative operation, and a presurgical clinical staging system. Ann Surg 1998;228:385-394.

15 Neuhaus P, Jonas S, Bechstein WO, et al: Extended resections for hilar cholangiocarcinoma. Ann Surg 1999;230:808-819.

16 Miyazaki M, Kato A, Ito H, et al: Combined vascular resection in operative resection for hilar cholangiocarcinoma: does it work or not. Surgery 2007;141:581-588.

17 Gerhards MF, van Gulik TM, de Wit LT, Obertop H, Gouma DJ: Evaluation of morbidity and mortality after resection for hilar cholangiocarcinoma - a single center experience. Surgery 2000;127:395-404.

18 Sakamoto Y, Sano T, Shimada K, et al: Clinical significance of reconstruction of the right hepatic artery for biliary malignancy. Langenbecks Arch Surg 2006;391:203-208.

19 Lee SG, Song GW, Hwang S, et al: Surgical treatment of hilar cholangiocarcinoma in the new era: the Asan experience. J Hepatobiliary Pancreat Surg 2010;17:476-489.

20 Kamiya S, Nagino M, Kanazawa H, et al: The value of bile replacement during external biliary drainage: an analysis of intestinal permeability, integrity, and microflora. Ann Surg 2004;239:510-517.
21 Kanazawa H, Nagino M, Kamiya S, et al: Synbiotics reduce postoperative infectious complications: a randomized controlled trial in biliary cancer patients undergoing hepatectomy. Langenbecks Arch Surg 2005;390: 104-113.

22 Kawasaki S, Imamura H, Kobayashi A, Noike T, Miwa S, Miyagawa S: Results of surgical resection for patients with hilar bile duct cancer: application of extended hepatectomy after biliary drainage and hemihepatic portal vein embolization. Ann Surg 2003;238:84-92.

23 Hasegawa S, Ikai I, Fujii H, Hatano E, Shimahara Y: Surgical resection of hilar cholangiocarcinoma: analysis of survival and postoperative complications. World J Surg 2007;31: 1256-1263.

24 Gazzaniga GM, Filauro M, Bagarolo C, Mori L: Surgery for hilar cholangiocarcinoma: an Italian experience. J Hepatobiliary Pancreat Surg 2000;7:122-127.

25 Nakeeb A, Tran KQ, Black MJ, et al: Improved survival in resected biliary malignancies. Surgery 2002;132:555-564.

26 Havlik R, Sbisa E, Tullo A, et al: Results of resection for hilar cholangiocarcinoma with analysis of prognostic factors. Hepatogastroenterology 2000;47:927-931.

$\checkmark 27$ Klempnauer J, Ridder GJ, von WR, Werner M, Weimann A, Pichlmayr R: Resectional surgery of hilar cholangiocarcinoma: a multivariate analysis of prognostic factors. J Clin Oncol 1997;15:947-954.

28 Abdel WM, Fathy O, Elghwalby N, et al: Resectability and prognostic factors after resection of hilar cholangiocarcinoma. Hepatogastroenterology 2006;53:5-10.

29 Jarnagin WR, Bowne W, Klimstra DS, et al: Papillary phenotype confers improved survival after resection of hilar cholangiocarcinoma. Ann Surg 2005;241:703-7124.

-30 Seyama Y, Kubota K, Sano K, et al: Longterm outcome of extended hemihepatectomy for hilar bile duct cancer with no mortality and high survival rate. Ann Surg 2003;238: 73-83. 